Gelanggang Olahraga: Jurnal Pendidikan Jasmani dan Olahraga

Volume 3, Nomor 1, Juli-Desember 2019

e-ISSN : 2597-6567

p-ISSN : 2614-607X

DOI : https://doi.org/10.31539/jpjo.v3i1.828

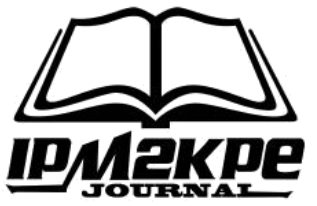

\title{
PENGARUH LATIHAN SHUTTLE-RUN DAN ZIG-ZAG RUN TERHADAP KELINCAHAN ATLET TAEKWONDO
}

\author{
Citra Azhariat Malasari \\ Universitas Muhammadiyah Kotabumi \\ citra.ciyus@gmail.com
}

\begin{abstract}
ABSTRAK
Tujuan dari penelitian ini adalah untuk mengetahui keefektifan latihan shuttle-run dan zig-zag run dalam meningkatkan kelincahan atlet taekwondo. Penelitian ini menggunakan metode quasi exsperimen dengan rancangan pre-test dan post-test design control group. Hasil penelitian menunjukkan, (1) latihan shuttle run memberikan pengaruh yang berarti terhadap peningkatan kelincahan $\left(\mathrm{t}_{\mathrm{hit}}=61,42>\right.$ $\mathrm{t}_{\text {tab }}=2,26$ ); (2) latihan ziq-zaq run memberikan pengaruh yang berarti terhadap peningkatan kelincahan $\left(t_{\text {hit }}=169,06>t_{\text {tab }}=2,26\right)$; (3) latihan ziq-zaq run lebih efektif dalam meningkatkan kelincahan dibandingkan dengan latihan shuttle run $\left(\mathrm{t}_{\text {hit }}=25,64>\mathrm{t}_{\mathrm{tab}}=2,26\right)$. Simpulan, latihan dengan metode zig-zag run lebih efektif dalam meningkatkan kelincahan atlet taekwondo
\end{abstract}

Kata Kunci: Shuttle-Run, Zig-Zag Run, Kelincahan, Taekwondo.

\begin{abstract}
The purpose of this study was to determine the effectiveness of shuttle run and zigzag run exercises in increasing the agility of taekwondo athletes. This study uses a quasi-experimental method with a pre-test and post-test design control group design. The results showed, (1) shuttle run training had a significant effect on increasing agility (thit $=61.42>$ ttab $=2.26)$; (2) ziq-zaq run exercises have a significant effect on increasing agility (thit $=169.06>t$ tab $=2.26) ;(3)$ ziq-zaq run exercises are more effective in increasing agility compared to shuttle run exercises (thit $=25.64>$ ttab $=2.26$ ). In conclusion, training with the zig-zag run method is more effective in increasing the agility of taekwondo athletes.
\end{abstract}

Keywords: Shuttle-Run, Zig-Zag Run, Agility, Taekwondo.

\section{PENDAHULUAN}

Taekwondo adalah salah satu cabang olahraga beladiri berprestasi. Olahraga ini tidak hanya mengajarkan aspek fisik semata, seperti keahlian dalam bertarung melainkan juga sangat menekankan pengajarkan aspek disiplin mental. Taekwondo mengandung aspek filosofi yang mendalam sehingga dengan mempelajari Taekwondo, pikiran, jiwa, dan raga kita secara menyeluruh akan ditumbuhkan dan dikembangkan. Taekwondo sudah seharusnya menunjukan kondisi fisik yang baik, mental yang kuat dan semangat yang tinggi.

Taekwondo membutuhkan kondisi fisik yang prima, hal ini disebabkan oleh intensitas gerakan yang tinggi dalam melaksanakan setiap teknik gerakan. Salah satu kondisi fisik yang harus dimiliki adalah kelincahan. Kelincahan merupakan salah satu komponen fisik yang sangat penting dalam kemajuan teknik 
gerakan. Menurut Widiastuti (2011), kelincahan adalah kemampuan untuk mengubah arah atau posisi tubuh dengan cepat yang dilakukan bersama-sama dengan gerakan lainnya. Menurut Mappaompo (2011) kelincahan adalah suatu bentuk gerakan yang mengharuskan seorang atau pemain untuk bergerak dengan cepat dan mengubah arah serta tangkas. Pemain yang lincah adalah pemain yang bergerak tanpa kehilangan keseimbangan dan kesadaran akan posisi tubuhnya. Sesuai dengan penjelasan diatas kelincahan sangat diperlukan demi terwujudnya sebuah prestasi dan keberhasilan teknik gerakan.

Hasil penelitian Fatahilah (2018) kelincahan memberikan kontribusi terhadap kemampuan dribbling bolabasket. Atlet yang tidak mempunyai kelincahan maka akan kehilangan keseimbangan sehingga akan menjadi penghambat terlaksananya sebuah prestasi dalam olahraga Taekwondo. Penelitian sebelumnya yang dilakukan oleh Udam (2017) tentang pengaruh latihan shuttlerun dan zig-zag terhadap kemampuan dribbling bola pada siswa sekolah sepakbola (SSB) Immanuel usia 13-15 di Kabupaten Jayapura. Hasil penelitian menunjukkan: (1) Ada pengaruh latihan dengan menggunakan metode latihan Shuttle-run terhadap kemampuan dribbling pada Siswa Sekolah Bola (SSB) Imanuel usia 13-15 tahun.; (2) Ada pengaruh latihan dengan menggunakan metode latihan Zig-zag terhadap kemampuan dribbling pada Siswa Sekolah Bola (SSB) Imanuel usia 13-15 tahun; (3) Latihan dengan metode Zig-zag lebih efektif dalam meningkatkan kemampuan dribbling bola pada siswa sekolah sepak bola (SSB) Imanuel.

Jika ditinjau dari pertandingan dan latihan, kelincahan atlet taekwondo yang ada di Dojang kota Bandar Lampung masih dapat dikatakan rendah. Terbukti pada saat mengikuti pertandingan beberapa waktu lalu, penulis melihat dan mengamati langsung dan tampak kurang lincahnya gerakan atlet pada saat menghindari serangan lawan sehingga lawan dengan mudahnya mengantisipasi serangan yang diberikan. Pertandingan taekwondo yang terdiri dari 3 ronde dan tiap rondenya berdurasi 1,5 menit. Dalam pertandingan ini, kelincahan sangat dibutuhkan yaitu pada saat melakukan serangan, pergantian step dan melakukan counter untuk menghindari serangan dari lawan. Apabila atlet tidak memiliki kelincahan, maka akan susah untuk mengantisipasi serangan lawan. Selain itu, kelincahan dibutuhkan pada saat atlet melakukan tendangan seperti tendangan doliyo chagi, dwi chagi, dolke chagi dan yeop hurigi yang membutuhkan kecepatan dalam berputar dan kelincahan dalam merubah arah dan gerak tubuh.

Permasalahan yang telah diuraikan merupakan dasar kemerosotan kondisi fisik atlet salah satunya kurang memiliki kelincahan dalam bergerak. Adapun macam-macam bentuk latihan kelincahan menurut Harsono (1988) yaitu shuttle run, zig-zag run, wind sprint, squart trast, dot drill, tree coner drill, down the-line drill, grass drill, starting dan stoping run. Banyaknya bentuk-bentuk latihan kelincahan tersebut, penulis tertarik untuk mencoba melihat pengaruh latihan shuttle run dan zig-zag run dalam meningkatkan kelincahan atlet. Maka dari itu perlu dikaji dan dilihat sejauh mana pengaruh metode latihan shuttle run dan zigzag run terhadap kelincahan atlet Taekwondo di Dojang Kota Bandar Lampung. Berdasarkan hal di atas penulis tertarik untuk mengadakan penelitian dengan harapan bahwa dapat meningkatkan unsur kelincahan bagi atlet sehingga prestasi dapat dicapai. 


\section{KAJIAN TEORI}

\section{Hakikat Shuttle Run}

Shuttle Run merupakan salah satu latihan untuk meningkatkan kelincahan. Menurut Harsono dalam Udam (2017) Shuttle Run merupakan bentuk latihan kelincahan umum,latihan ini terdiri dari dua titik yang masing-masing titik berjarak $4-5$ meter. Hal tersebut dikarenakan kalau jarak yang terlalu jauh dikhawatirkan pemain atau siswa setelah beberapa kali melakukan lari bolak-balik tidak mampu lagi mengembalikan tubuhnya dengan cepat disebabkan oleh faktor kelelahan. Cara melakukannya yaitu lari bolak balik dilakukan secepat mungkin sebanyak 8 kali dalam jarak 5 meter. Setiap kali sampai pada suatu titik sebagai batas, maka secepatnya berusaha mengubah arah menuju titik lainnya. Perlu diperhatikan bahwa jarak antara kedua titik tidak terlalu jauh serta jumlah ulangan tidak terlalu banyak sehingga tidak akan menyebabkan kelelahan bagi si pelaku. Dalam hal ini yang perlu diperhatikan adalah kemampuan mengubah arah secepat mungkin pada saat bergerak. Menurut Mappaompo (2011) kelincahan adalah suatu bentuk gerakan yang mengharuskan seorang atau pemain untuk bergerak dengan cepat dan mengubah arah serta tangkas. Pemain yang lincah adalah pemain yang bergerak tanpa kehilangan keseimbangan dan kesadaran akan posisi tubuhnya. Shuttle Run adalah tes untuk mengukur kelincahan kaki, tetapi dalam tes Shuttle Run testi juga harus memindahkan balok dengan jarak 8 x 5 meter sehingga testi juga harus lincah dalam mengambil balok dengan waktu yang cepat sehingga menempuh jarak 40 M (Kementrian Pemuda dan Olahraga Tahun 2014), Juklak Tes dan Evaluasi Perkembangan hasil PPLP/SKO/PPLM.

\section{Hakikat Ziq-Zag Run}

Dalam kamus lengkap Bahasa Indonesia yang ditulis oleh Aditia dalam Tufik (2008) yaitu berbelok - belok atau kata lain zig-zag run merupakan gerak dari satu tempat lain yang dilakukan dengan berbelok-belok. Dapat disimpulkan latihan zig-zag run merupakan bentuk latihan kelincahan dengan menggunakan tonggak atau patok. Dimana dalam pelaksanaan atlet berlari secepat mungkin dengan berbelok-belok dari satu daerah ke daerah lain melewati beberapa patok yang ada dengan tidak melupakan prinsip-prinsip latihan zig-zag run adalah berlari secepat mungkin diantara dua batas yang bejarak kira-kira 2,4 meter untuk memberikan tantangan, latihan ini dapat dilakukan dengan adu cepat.

Kelincahan sangat berperan dalam melakukan serangan seperti pada tendangan $d w i$ chagi (tendangan kebelakang) dan pada saaat melakukan counter untuk mengatisipasi serangan lawan seperti melakukan tendangan pekta chagi atau mad badak chagi. Keseluruhan itu sangat membutuhkan kecepatan, kekuatan,kelenturan dan kelincahan agar bias memperoleh point.

Tujuan latihan zig-zag run adalah untuk menguasai keterampilan lari, menghindar dari berbagai halangan baik orang maupun benda yang ada di sekeliling (Wedana, 2014). Sesuai dengan tujuannya zig-zag run dibedakan menjadi dua, yaitu: 1) latihan zig-zag run untuk mengukur kelincahan seseorang meliputi; a) melatih lari segi tiga dengan ukuran garis segitiga yang telah ditentukan, b) latihan lari bentuk bintang dengan ukuran garis berbentuk bintang yang telah ditentukan, 2) latihan zig-zag run untuk merubah arah gerak tubuh atau bagian tubuh meliputi; a) latihan lari angka delapan, berlari mengikuti angka 
delapan, b) berlari dengan melewati rintangan, pada saat berlari akan berbentuk garis zig-zag.

\section{Hakikat Metode Latihan}

Setiap pelatih Pembina olahraga dalam memberikan latihan harus menggunakan metode latihan, karena dengan menggunakan metode latihan maka latihan dapat direncanakan dan dilaksanakan sesuai dengan tujuan dan kondisi yang ada. Metode latihan menurut Syafruddin (1996) adalah cara-cara yang digunakan secara terencana dan sistematis dan terorientasi pada tujuan. Dalam upaya untuk meningkatkan kemampuan fisik ataupun keterampilan pada suatu cabang olahraga, sering kali orang sudah berlatih walaupun hanya melakukan kegiatan satu atau dua kali saja setiap minggu, hal ini disebabkan karena pengertian tentang latihan belum dipahami dengan benar.

Menurut Nossek dalam Udam (2017) latihan adalah suatu proses atau periode waktu yang berlangsung selama beberapa tahun, sampai atlet tersebut mencapai standar penampilan tinggi. Menurut Nossek dalam Udam (2017) latihan adalah suatu proses atau periode waktu yang berlangsung selama beberapa tahun, sampai atlet tersebut mencapai standar penampilan tinggi. Menurut Tohar dalam Udam (2017) latihan suatu proses kerja yang harus dilakukan secara sistematis, berulang-ulang, berkesinambungan, dan makin lama jumlah beban yang diberikan semakin meningkat. Berulang-ulang maksudnya ialah agar gerakan-gerakan yang semula sukar dilakukan menjadi semakin mudah, otomatis, dan relektif pelaksanaannya sehingga semakin menghemat energi. Kian hari maksudnya ialah setiap kali secara periodik, segera setelah tiba saatnya untuk ditambah bebannya, jadi bukan berarti setiap hari.

\section{Hakikat Taekwondo}

Taekwondo adalah olahraga beladiri modern yang berakar pada beladiri tradisonal Korea. Suryadi (2002) menyatakan Taekwondo merupakan olahraga beladiri nasional Korea dan merupakan olahraga beladiri yang paling banyak diminati di dunia. Dalam Olympiade, taekwondo merupakan olahraga beladiri yang banyak dipertandingkan. Tae Kwon Do yang terdiri 3 (tiga) kata: tae berarti kaki/menghancurkan dengan teknik tendangan, kwon berarti tangan/menghantam dan mempertahankan diri dengan teknik tangan, do yang berarti seni atau cara mendisplinkan diri.

Jadi, Taekwondo merupakan seni beladiri yang menggunakan teknik kaki dan tangan kosong, dimana pokok dari konsep Taekwondo adalah gabungan dari kekuatan, kecepatan dan ketepatan. Tiga materi terpenting dalam berlatih taewondo adalah Poomse (jurus), Kyukpa (teknik pemecahan) dan Kyoruki (tarung). Dalam belajar taekwondo, Poomse Tae Geuk merupakan salah satu pelajaran pokok bagi orang yang mempelajari taekwondo. Pelajaran tersebut terutama menjadi materi wajib dalam Seunggeub Shimsa (ujian kenaikan tingkat) hingga mencapai Sabuk Hitam. Materi poomse dalam latihan taekwondo dibagi dua, yaitu poomse yang diperuntukan bagi yang belum mencapai tingkatan sabuk hitam (Tae Geuk I-VII) dan poomse bagi tingkatan sabuk hitam (Koryo - Ilyo).

Perkembang Taekwondo di Indonesia tampaknya akan terus berkembang pesat seiring prestasi yang diraih para atlet-atletnya, namun untuk pencapaian puncak prestasi tentunya hanya akan dicapai dari proses suatu pembinaan yang 
baik. Oleh karena itu PBTI juga telah mengirimkan pengurus maupun pelatihanpelatihan untuk mengikuti seminar-seminar General Assembly, maupun pertemuan-pertemuan lainya yang diselenggarakan oleh WTF.

\section{METODE PENELITIAN}

Penelitian ini dilaksanakan di Dojang Saburai, salah satu tempat latihan yang ada di Kota Bandar Lampung di bawah naungan PBTI (Pengurus Besar Taekwondo Indonesia). Waktu penelitian ini dilaksanakan 7 Juli 2019 sampai dengan 18 Agustus 2019. Desain yang digunakan dalam penelitian ini adalah Pretest Post-test Group Design. Dengan kata lain desain penelitian ini menggunakan data yaitu dengan melakukan pre-test dan post-test.

Populasi dalam penelitian ini adalah seluruh atlet taekwondo di Dojang Saburai yang terdiri dari 20 orang atlet putra dan 18 orang atlet putri. Dalam penelitian ini atlet putra merupakan sampel. Adapun sampel yang digunakan dalam penelitian ini adalah sebanyak 20 atlet putra yang masih aktif latihan di Dojang Saburai Kota Bandar Lampung. Data yang diperoleh dalam penelitian ini adalah data Shuttle-run dan Zig-zag run terhadap peningkatan kelincahan atlet taekwondo di Dojang Saburai.

Penelitian ini menggunakan metode penelitian eksperimen semu (Quasi Exsperimen). Menurut Nazir (2003), “ Penelitian eksperimen semu adalah penelitian yang mendekati percobaan sesungguhnya dimana tidak mungkin mengadakan control memanipulasikan semua variable yang relevan" dilihat dari lokasi penelitian maka penelitian ini termasuk jenis penelitian eksperimen lapangan.

Pengukuran pertama dilakukan melalui tes awal (pre-test) dan pengukuran kedua melalui tes akhir (post-test). Tes awal dilakukan dengan tujuan untuk mengambil data sebelum diberikan treatment (Latihan), dan tes akhir dilakukan untuk mengambil data setelah diberikan treatment selama 18 kali pertemuan. Penetapan kelompok dalam penelitian ini dilakukan dengan cara "Ordinally Meatching Pairing" setelah tes awal yang selanjutnya dibagi dua kelompok dengan sistem zig-zag.

\section{HASIL PENELITIAN}

Untuk mengetahui ada tidak adanya pengaruh signifikan dari perlakukan (metode latihan) serta untuk mengetahui ada atau tidak adanya perbedaan keefektifan kedua latihan, yaitu latihan Shuttle-run dan Zig-zag run, maka dilakukan pengujian data dengan menggunakan dua metode, yaitu uji parsial ( $\mathrm{t}$ parsial) dan uji t (Sujarweni, 2014).

Table 1

Hasil pengolahan data

\begin{tabular}{|c|c|c|c|c|c|c|}
\hline \multirow{2}{*}{ Variabel } & \multicolumn{5}{|c|}{ Uji-t } & \multirow{2}{*}{ Ket } \\
\hline & $\mathrm{t}_{\text {hit }}$ & $\mathrm{t}_{\mathrm{tab}}$ & $\mathrm{df}$ & (P) & $(\alpha)$ & \\
\hline $\begin{array}{c}\text { Shuttle } \\
\text { run }\end{array}$ & 61,42 & 2,26 & 9 & $\begin{array}{c}0,00 \\
0\end{array}$ & $\begin{array}{c}0,0 \\
5\end{array}$ & Sig. \\
\hline $\begin{array}{c}\text { Ziq-zaq } \\
\text { run }\end{array}$ & 169,06 & 2,26 & 9 & $\begin{array}{c}0,00 \\
0\end{array}$ & $\begin{array}{c}0,0 \\
5\end{array}$ & Sig. \\
\hline
\end{tabular}

Sumber: Data Primer yang Diolah, 2019 


\section{Pengaruh Latihan Shuttle Run Terhadap Kelincahan}

Berdasarkan hasil analisis, terlihat bahwa uji t pada tes akhir kelincahan atlet Taekwondo Dojang Saburai dengan menggunakan latihan Shuttle-run memiliki nilai $\mathrm{t}_{\mathrm{hit}}=61,42$ dan nilai $\mathrm{t}_{\mathrm{tab}}=2,26$ dengan $\mathrm{df}=9$ pada taraf signifikansi 5\%. Nilai thitung $>$ ttabel, dan nilai Probabilitas $(\mathrm{P})$ sebesar $0,000(<0,05)$, maka dapat disimpulkan bahwa Ho ditolak dan Ha diterima, artinya adalah ada pengaruh yang signifikan terhadap peningkatan kelincahan.

Hasil penelitian ini sejalan dengan hasil penelitian yang dilakukan oleh Irawan (2008), hasil penelitian menunjukan bahwa: ada peningkatan kemampuan keterampilan menggiring bola setelah peserta ekstrakurikuler sepak bola mengikuti program latihan Shuttle Run dengan $\mathrm{t}_{\text {hit }} 14,736>\mathrm{t}_{\mathrm{tab}} 2,26$.

\section{Pengaruh Latihan Ziq-Zaq Run Terhadap Kelincahan}

Berdasarkan hasil analisis, terlihat bahwa uji t pada tes akhir kelincahan atlet Taekwondo Dojang Saburai dengan menggunakan latihan Ziq-zaq-run memiliki nilai $t_{\text {hit }}=169,06$ dan nilai $t_{\text {tab }}=2,26$ dengan $\mathrm{df}=9$ pada taraf signifikansi 5\%. Nilai thitung > ttabel, dan nilai Probabilitas $(\mathrm{P})$ sebesar 0,000 $(<$ 0,05), maka dapat disimpulkan bahwa Ho ditolak dan Ha diterima, artinya adalah ada pengaruh yang signifikan terhadap peningkatan kelincahan.

Hasil penelitian ini sejalan dengan hasil penelitian yang dilakukan oleh Dudut (2012), dengan judul penelitian Pengaruh Latihan Shuttle Run dan Zig-zag Run Terhadap Kelincahan Atlet Sepakbola Usia 13-15 Ssb Adiraga Putra Magelang. Hasil hipotesis menunjukkan bahwa: (1) ada perbedaan yang signifikan pada kelompok eksperimen Shuttle Run, dengan $t_{\text {hitung }}=10.487$ dan $\mathrm{t}_{\text {tabel}=2.16}$ dan nilai signifikansi $0.000(<0.05)$, dengan demikian Ha diterima. Kenaikan persentase sebesar $15.82 \%$. (2) Ada perbedaan yang signifikan pada kelompok eksperimen Zig-zag Run, dengan $t_{\text {hitung }} 6.355$ dan $t_{\text {tabel }} 2.16$, dan nilai signifikansi $0.000(<0.05)$, dengan demikian Ha diterima. Kenaikan persentase sebesar 18.19\%. (3) Latihan Zig-zag Run lebih efektif untuk meningkatkan kelincahan, kenaikan persentase kelompok eksperimen Shuttle Run sebesar $15.82 \%$ dan kenaikan persentase kelompok eksperimen Zig-zag Run sebesar $18.19 \%$, dengan demikian Ha diterima. Selisih pos test sebesar 0.403 detik.

\section{PEMBAHASAN}

Berdasarkan hasil penelitian, dapat dilihat bahwa pada nilai rata-rata pre test dengan metode latihan shuttle-run dan zig-zag run, memiliki nilai rerata yang berbeda. Namun demikian, nilai ini tidak dapat dijadikan acuan dalam menentukan metode mana yang lebih efektif, karena untuk menentukan metode yang lebih efektif diantara metode latihan shuttle-run dan metode zig-zag dalam meningkatkan kelincahan, hanya dapat dilakukan dengan melihat nilai kenaikan dari kedua metode tersebut. Ada perbedaan pengaruh yang signifikan dari hasil post test antara kelompok latihan shuttle run dengan latihan ziq-zaq run terhadap peningkatan kelincahan dimana $\mathrm{t}_{\mathrm{hit}}=25,64>\mathrm{t}_{\mathrm{tab}}=2,26$. 
Table 2

Rerata Peningkatan Kelincahan

\begin{tabular}{cccc}
\hline $\begin{array}{c}\text { Kelompok } \\
\text { Latihan }\end{array}$ & $\begin{array}{c}\text { Pre } \\
\text { test }\end{array}$ & $\begin{array}{c}\text { Post } \\
\text { test }\end{array}$ & Peningkatan \\
\hline Shuttle run & 14,53 & 12,47 & 2,06 \\
\hline Ziq-zaq run & 14,52 & 11,83 & 4,64 \\
\hline
\end{tabular}

Berdasarkan perhitungan tersebut, maka hipotesis ketiga yang diajukan dalam penelitian ini diterima. Hal ini sesuai dengan pendapat Sudjana (2002) yang mengatakan bahwa apabila $t_{\text {hitung }}$ lebih besar dari $t_{\text {tabel, }}$ maka Ha diterima dan Ho ditolak. Artinya bahwa latihan Ziq-zaq run lebih menunjukkan peningkatan yang lebih berarti bila dibandingkan dengan latihan Shuttle run.

\section{SIMPULAN}

Ada pengaruh latihan dengan menggunakan metode latihan Shuttle-run terhadap peningkatan kelincahan atlet Taekwondo Dojang Saburai Kota Bandar Lampung. Ada pengaruh latihan dengan menggunakan metode latihan Zig-zag run terhadap peningkatan kelincahan atlet Taekwondo. Latihan dengan metode Zigzag run lebih efektif dalam meningkatkan kelincahan atlet Taekwondo

\section{DAFTAR PUSTAKA}

Dudut, A. (2012). Pengaruh Latihan Shuttle Run Dan Zig-zag Run Terhadap Kelincahan Atlet Sepakbola Usia 13-15 Ssb Adiraga Putra Magelang. Tesis Tidak Dipublikasikan.

Fatahillah, A. (2018). Hubungan Kelincahan dengan Kemampuan Dribbling pada Siswa Ekstrakurikuler Bola Basket. Gelanggang Olahraga: Jurnal Pendidikan Jasmani Dan Olahraga (JPJO), 1(2), 11-20. https://doi.org/https://doi.org/10.31539/jpjo.v1i2.131

Guspa, E.,I. (2008). Perbedaan Pengaruh Latihan Shuttle Run dan Lari Zig-zag terhadap Kemampuan Menggiring dalam Permainan Sepak Bola Peserta Ekstrakurikuler di SMP Negeri 2 Bantul. Tesis Tidak Dipublikasikan.

Harsono. (1988). Coaching dan Aspek-Aspek Psikologi Dalam Coaching. Jakarta: Depdikbud, Dirjen Dikti P2LPTK.

Mappaompo, M.,A. (2011). Kontribusi Koordinasi Mata-Kaki dan Kelincahan Terhadap Kemampuan Menggiring Bola Dalam Permainan Sepakbola Club Bilopa Kabupaten Sinjai. Jurnal ILARA, 2 (1),96-101.

Nazir.,M. (2003). Metode Penelitian. Jakarta: Ghalia Indonesia

Sudjana, N. (2002). Metode Statistik. Bandung: Tarsito.

Sujarweni, V.,W. (2014). SPSS Untuk Penelitian. Yogyakarta: Pustaka Baru Press.

Suryadi, V.,Y. (2002). Taekwondo Poomse Tae Geuk. Jakarta. PT. Gramedia.

Syafruddin. (1996). Pengantar Ilmu Melatih. Padang: FPOK IKIP.

Tufik, F. (2008). Perbedaan Hasil Latihan Dribbling Ziq-Zaq dan Dribbling Bolak-Balik terhadap Kemampuan Dribbling Pemain Sepakbola SMPN 13 Padang. FIK UNP.

Udam, M. (2017). Pengaruh Latihan Shuttle-Run dan Zig-Zag terhadap Kemampuan Dribbling Bola Pada Siswa Sekolah Sepakbola (SSB) Imanuel Usia 13-15 Di Kabupaten Jayapura. Jurnal PJOK. 3(1), 58-71. 
2019. Gelanggang Olahraga: Jurnal Pendidikan Jasmani dan Olahraga 3(1) 81-88

Wedana, I.,M.,A.,Sudiana, I., Wahyuni, P.,D.,S. (2014). Pengaruh Pelatihan ZigZag Run Dan Lari 60 M terhadap Volume Oksigen Maksimal (Vo2maks). 2014. Volume 1. Singaraja: Universitas Pendidikan Ganesha.

Widiastuti. (2011). Tes dan Pengukuran Olahraga. Jakarta : PT. Bumi Timur Jaya. 